\title{
CAPÍTULO 12: ESTUDO DO APROVEITAMENTO DE SUBPRODUTOS AGROINDUSTRIAIS: ALTERNATIVAS PARA OS RESÍDUOS GERADOS PELAS INDÚSTRIAS DE LATICÍNIOS
}

\section{CHAPTER 12: STUDY OF THE APPROVAL OF AGRO-INDUSTRIAL BY- PRODUCTS: ALTERNATIVES FOR WASTE GENERATED BY THE DAIRY INDUSTRIES}

\author{
Débora Karina Ferreira de Lira ${ }^{1}$; Gerla Castello Branco Chinelate ${ }^{2}$
}

\begin{abstract}
Resumo
$\mathrm{Na}$ indústria de laticínios existem subprodutos com propriedades funcionais provenientes do processo de fabricação de alguns alimentos, como exemplos o soro de leite, oriundo da produção de queijos, também conhecido como soro de queijo e o leitelho, obtido do processo de produção da manteiga. Eles possuem elevado teor nutricional em sua composição e é sugerido no enriquecimento ou desenvolvimento de novos produtos. Apesar dos seus benefícios, ao serem descartados de forma inadequada, eles são considerados altamente poluentes devido sua alta carga orgânica. Em virtude disso, o presente artigo aborda o tema da utilização do soro de leite e leitelho na elaboração de produtos alimentícios, como também identificar as tecnologias possíveis para utilizá-los como ingredientes. A metodologia utilizada consistiu em uma revisão bibliográfica com levantamento de informações sobre o tema por meio de artigos e dissertações nacionais. Nesta revisão observou-se que diversos trabalhos estão sendo realizados, comprovando a eficiência desses subprodutos em alimentos, mas que ainda assim, comparado ao volume gerado e a quantidade de opções de fabricação, o aproveitamento e valorização no âmbito comercial ainda é baixo. Por essa razão será apresentada o uso desses subprodutos em diversos tipos de alimentos, contribuindo para uma maior valorização comercial.
\end{abstract}

Palavras-Chave: Aproveitamento, subprodutos, soro de leite, leitelho.

\begin{abstract}
In the dairy industry there are by-products with functional properties from the manufacturing process of some foods, such as whey, derived from cheese production, also known as cheese whey and buttermilk, obtained from the butter production process. They have a high nutritional content in their composition and are suggested in the enrichment or development of new products. Despite their benefits, when improperly disposed of, they are considered highly polluting due to their high organic load. As a result, this article addresses the issue of using whey and buttermilk in the preparation of food products, as well as identifying possible technologies for using them as ingredients. The methodology used consisted of a bibliographic review with gathering information on the theme through articles and national dissertations. In this review it was observed that several works are being carried out, proving the efficiency of these by-products in food, but that, still, compared to the volume generated and the quantity of manufacturing options, the use and valorization in the commercial scope is still low. For this reason, the use of these by-products in different types of food will be presented, contributing to a greater commercial valorization.
\end{abstract}

Keywords: Utilization, by-products, whey, buttermilk.

\footnotetext{
${ }^{1}$ Engenharia de Alimentos, Universidade Federal do Agreste de Pernambuco, deborakarina.ufrpe@gmail.com

${ }^{2}$ Doutora, Professora do curso de Engenharia de Alimentos da Universidade Federal do Agreste de

Pernambuco, gerla.chinelate@ufape.edu.br
} 


\section{Introdução}

O Brasil ocupa no mundo a terceira posição de maior produtor de leite e é responsável pela produção de diversos produtos lácteos (EMBRAPA, 2019). Diante desse cenário e a crescente preocupação com o desenvolvimento de produtos sustentáveis, as indústrias alimentícias estão cada vez mais pressionadas a reduzirem os resíduos produzidos durante o processamento de seus insumos, principalmente as indústrias de laticínios (DELGADO, 2007). Desse modo, a destinação do que se tornaria resíduo industrial, para fabricação de alimentos inovadores, se apresenta como uma excelente alternativa para o seu não descarte.

De acordo com Kubota et al. (2012), a indústria de alimentos se encontra em constante busca pela inovação, com eficiência em seus processos produtivos e na geração de resultados em seus produtos finais, levando sempre em consideração a alta competitividade e concorrência junto aos consumidores mais bem informados e exigentes. Em razão disso, o mercado de alimentos e bebidas tem expandido a tentativa de satisfazer o consumidor no lançamento de produtos.

No que se refere ao setor lácteo, a implementação de inovações também faz parte do seu cenário industrial principalmente por dois motivos: primeiro, o leite é uma matéria-prima bastante perecível e precisa de buscas por maior qualidade e durabilidade em seus produtos, e segundo, a preocupação emergente com o desenvolvimento sustentável de produtos, devido aos seus efluentes agroindustriais (DELGADO; BARIN-CRUZ, 2007). O que se refere ao último, Vourch et al. (2008) ressalta que os efluentes líquidos constituem a principal fonte de poluição dessa indústria em razão da alta carga orgânica dos resíduos do leite e produtos derivados do leite.

O leite é a matéria-prima de origem animal básica na alimentação humana, constituída por uma série de componentes, como: água, lipídeos, carboidratos, proteínas e nutrientes. Ele é utilizado na produção de muitos alimentos como: bebida láctea, leite fermentado, coalhada, queijos, leite em pó, manteiga, creme de leite, requeijão, iogurte, doce de leite, leite pasteurizado, ricota, etc. (CRUZ et al., 2015).

É importante salientar que durante o processamento desses produtos, quantidades consideráveis de subprodutos são gerados. Por exemplo, a produção de queijo resulta em produção adicional de soro; produção de manteiga resulta em leitelho adicional; produção deóleo de manteiga resulta em soro cremoso adicional; etc. (BANASZEWSKA et al., 2014). Neste trabalho, serão destacados dois subprodutos que possuem grande potencial comercial e capacidade de poluição severa, caso descartado de forma incorreta: o soro de leite e o leitelho. 
O soro de leite é classificado pelo Regulamento de Inspeção Industrial e Sanitária de Produtos de Origem Animal - RIISPOA, no Art. 400 do decreto nº 9.013 (BRASIL, 2017) como o produto líquido de caráter lácteo extraído da coagulação do leite no processamento de queijos, de caseína e de produtos similares. Ele possui cerca da metade dos nutrientes originais do leite sendo abundante em componentes tais como: proteínas do soro, vitaminas hidrossolúveis, sais minerais e lactose (SMITHERS, 2008).

As proteínas presentes no soro do leite oferecem muitos benefícios para o homem, como: reparação celular, construção e reparação de músculos e ossos, dão energia ao corpo, além de outros benefícios que estão ligados a processos metabólicos, como atividade imunoestimulante, proteção ao sistema cardiovascular e atividade antimicrobiana e antiviral (SGARBIERI, 2005; HARAGUCHI et al., 2006).

No entanto, como resíduo, proporciona malefícios ao meio ambiente e à sociedade. Ao ser descartado, se torna um dos efluentes líquidos que mais contribuem para a alta carga poluidora das indústrias de laticínios. Dez litros de soro descartado incorretamente equivalem à poluição causada por cinco habitantes (MOREIRA; SILVA; ANTUNES, 2000), além de ser cem vezes mais poluente que o esgoto doméstico (SILVA, 2011). De acordo com Rosenthal (2016), o aproveitamento desse subproduto teve um aumento com a chegada de instalações de unidades industriais de concentração e secagem no Brasil, mas ainda assim, o volume descartado ou subutilizado ainda é elevado.

Outro subproduto a ser discutido neste trabalho é o leitelho, o qual é classificado também pelo RIISPOA no Art. 404 (BRASIL, 2017), como o produto lácteo liberado durante o batimento do creme pasteurizado para a produção de manteiga. Assim como o soro de leite, o aproveitamento total do leitelho ainda é um grande desafio para as indústrias brasileiras. Já no mercado internacional, ele é um produto bastante popular e consumido como um tipo de bebida láctea ou um tipo de leite fermentado, também chamado de fermented buttermilk, frequentemente consumido com cereais ou como substituto do leite fresco (ANTUNES et al., 2012).

O leitelho contém a maior parte da proteína encontrada no leite, além de possuir vitaminas, minerais e propriedades funcionais devido a presença de fosfolipídios, que por sua vez são provenientes das membranas fragmentadas dos glóbulos de gordura do leite interrompidas durante a agitação. A sua presença influencia na redução do colesterol no sangue, inibição e impedimento do desenvolvimento de bactérias que se aderem as paredes do trato gastrointestinal (FONG; NORRIS; MACGIBBON, 2007; NOH; KOO, 2004). Em virtude dessas características, ele se apresenta como uma boa alternativa para formulações de 
novos produtos alimentícios, pois possui várias propriedades benéficas a saúde do consumidor.

Em resumo, os subprodutos discutidos contêm uma parte consideravelmente grande de nutrientes na sua composição. No entanto, por causa da elevada demanda biológica de oxigênio não devem ser misturados aos demais efluentes da indústria. Pelo contrário, devem ser captados e conduzidos separadamente, de modo a propiciar o seu aproveitamento na fabricação de outros produtos lácteos ou para utilização direta na alimentação de animais (SILVA, 2011).

Ao serem submetidos a tecnologias, produtos são gerados com alto teor de nutrientes e alimentos são enriquecidos pela possibilidade de utilizar os subprodutos como ingredientes, dando-lhes propriedades nutritivas, ou seja, potencial de fabricar alimentos funcionais que de acordo com Vidal et al. (2012) são aqueles que fornecem benefícios adicionais na alimentação do consumidor, os quais produzem efeitos fisiológicos ou metabólicos por meio do desempenho de algum nutriente, na manutenção das funções do organismo humano.

Diante do exposto, o presente artigo aborda vários estudos sobre alternativas de aproveitamento, afim de evitar impactos negativos ao meio ambiente e aproveitar os nutrientes presentes nas composições desses subprodutos.

\section{Desenvolvimento}

Este trabalho foi desenvolvido com base em artigos e dissertações nas diversas áreas de Ciência e Tecnologia de Alimentos que abordavam alternativas de aproveitamento do soro de leite e leitelho na elaboração de produtos, além de identificar as tecnologias de tratamento existentes para utilizá-los como ingredientes na formulação de alimentos.

\subsection{Discussão}

\subsubsection{Utilização do soro do leite}

A princípio, grande parte do soro de leite gerado no Brasil, provem de pequenas e médias queijarias, o que torna o investimento em tecnologia necessária para o beneficiamento do subproduto mais difícil (ALVES, 2014). No entanto, estudos sobre o problema de aproveitamento do soro já vem sendo realizado há alguns anos. Machado (2001) chega a comentar que é possível ter ações conjuntas que solucionem definitivamente esse problema, sendo elas: a adoção de programas para melhoria da qualidade nas indústrias e a implementação de unidades estratégicas bem localizadas para facilitar o encaminhamento do 
subproduto para uma unidade de processamento.

Durante a fabricação de queijos o soro representa $90 \%$ do volume do leite, pois para produzir $1 \mathrm{~kg}$ de queijo são necessários $10 \mathrm{~L}$ de leite, o que gera $9 \mathrm{~L}$ de soro (LEITE; BARROZO; RIBEIRO, 2012). A utilização desse soro ainda não é significativa no Brasil, uma vez que apenas cerca de $15 \%$ do soro de leite líquido é empregado como matéria-prima no setor tecnológico alimentício (ROHFLES, 2014). Este percentual é empregado na fabricação de algumas bebidas e alimentos.

Como bebidas podem ser encontradas processadas de diversas maneiras como UHT, pasteurizadas, bebidas lácteas fermentadas semelhantes ao iogurte, bebidas lácteas não fermentadas, soft-drinks, carbonatadas e em diversos sabores (LIMA; MADUREIRA; PENNA, 2002). Dentre elas, a produção de bebida láctea é uma das principais opções de aproveitamento do soro de leite no Brasil (SANTOS, 2008).

O Regulamento Técnico de Identidade e Qualidade de Bebidas Lácteas (BRASIL, 2005) define a bebida láctea como o produto resultante da mistura do leite e soro de leite, fermentadas ou não, adicionadas ou não de outros ingredientes. PESCUMA et al. (2010) comentam que essas bebidas com a presença do soro possuem muitos benefícios para o consumidor devido a ação de bactérias láticas na fermentação do soro, as quais realizam intensa atividade metabólica sobre os carboidratos, lipídeos, proteínas e peptídeos alergênicos que nele estão presentes. Promovendo assim, contribuições na digestibilidade, preservação, melhoria da textura e perfil sensorial do alimento.

Siqueira, Machado e Stamford (2013) realizaram um levantamento bibliográfico sobre bebidas lácteas a base de soro com adição de frutas e ressaltaram que essa combinação tem melhorado as características de aromas e sabor desse tipo de bebida, além de estimular o interesse em alcançar o consumidor devido as recomendações nutricionais do consumo de frutas e hortaliças. Estudos sobre a elaboração de bebidas lácteas com adição do soro e polpas de frutas: abacaxi (BRANDÃO et al., 2006); graviola (MATOS, 2009); umbu (SANTOS et al., 2006); manga (SANTOS et al., 2008); açaí (ZOELLNER et al., 2009); acerola (CRUZ et al., 2009); morango (CALDEIRA et al., 2010), (OLIVEIRA et al., 2006); pêssego (KEMPKA et al., 2008) e uva (KREUTZ; LEHN; SOUZA, 2012).

O soro do leite é também bastante utilizado na formulação de alimentos funcionais. Dentre os mais variados tipos de produtos funcionais, o soro do leite é encontrado comercialmente em barras de cereais, biscoitos, massas prebióticas, bebidas antioxidantes, chocolates probióticos, entre outros (BADISSERA et al., 2011). Segundo Alves (2014) 
durante a fabricação desses alimentos, o soro é utilizado na forma líquida ou em pó (obtidos através do uso de tecnologias de separação por membrana, evaporação à vácuo e secagem por atomização), possibilitando também a produção dos concentrados e isolados proteicos do soro.

Silva, (2011) fez a elaboração de um leite condensado a partir do soro de leite em pó, denominada pela autora de "mistura láctea", com intuito de substituir o leite condensado utilizado em sobremesas. As análises demonstraram que esse produto a base de soro de leite apresentou valores semelhantes ao tradicional, o que pode ser considerada uma ótima alternativa para sobremesas.

Também na área de sobremesas, Vettorello et al. (2017) fizeram uso do soro de leite para elaborar diferentes formulações de sorvete, substituindo o leite UHT por soro de leite em pó. Após a obtenção do produto final foram realizadas as seguintes análises: físicoquímicas de proteína, gordura e sólidos totais. Os resultados de todas as análises foram favoráveis ao desenvolvimento desse produto, com bom índice de aceitação sensorial.

Bedendo et al. (2019) discorreram sobre a substituição de leite em pó por concentrado proteico de soro de leite (WPC - WheyProteinConcentrate) e açúcar cristal por mascavo para elaboração de bolo sem glúten. A substituição dos ingredientes não influenciou a estrutura física do bolo e obtiveram uma boa aceitabilidade das amostras oferecidas, sendo assim, uma boa alternativa a ser introduzida numa alimentação mais saudável.

Soares et al. (2018) também fizeram a elaboração de bolos, só que sem adição de açúcar e com adição da proteína do soro de leite como substituto do trigo, avaliando o efeito das diferentes proporções da proteína do soro e manteiga. Os resultados de análises físicoquímicas e sensoriais do produto final apresentaram o teor maior de proteínas e menor teor de carboidratos totais, atingindo o objetivo do trabalho e sendo apropriados para o consumo por aqueles que possuem restrições de sacarose.

Arrais (2015) apresentou mais uma alternativa para o uso do soro, utilizando-o na fabricação de uma ricota funcional. De acordo com Pinto (2010), a ricota é constituída quase somente de proteínas do soro, sendo a albumina a principal e de globulina obtida através do soro de queijo. O trabalho citado elaborou uma ricota com a adição de soro e/ou inulina e/ou cultura probiótica com várias formulações e obteve resultados tecnologicamente viáveis para a reprodução desse produto.

Soares (2011) desenvolveu um iogurte probiótico aproveitando o soro de queijo de coalho fazendo avaliações de diferentes processos de pasteurização e concentração de leite em pó. Em todas as formulações não ocorreu a contaminação por bactérias deteriorantes e a 
contagem de bactérias lácteas foi de valor adequado, demonstrando que esse produto é uma alternativa viável para agregar valor ao subproduto.

Terra (2009) desenvolveu uma mortadela substituindo a água que seria empregada na sua elaboração por três proporções diferentes de soro de leite líquido. Essa substituição não exerceu influência significativa nas características sensoriais, pH, coloração, estabilidade da emulsão e líquido liberado após tratamento térmico das mortadelas. Logo, o soro pode ser empregado na fabricação de mortadelas e enriquecer esse produto com suas propriedades nutritivas.

Carvalho et al. (2015), desenvolveram uma formulação de pão de queijo fazendo a substituição parcial ou total do leite por diferentes concentrações de soro de leite. Por meio de avaliações de análises sensoriais do produto final, foi possível concluir que o pão de queijo enriquecido com soro de leite não obteve diferença significativa em relação ao produto padrão, além de ter uma boa aceitação dos consumidores. Fabricação de outros pães com o uso do soro: pão francês (SILVA et al., 2011) e pão de forma (ARAÚJO; ARAÚJO; SAMPAIO, 2011; CALDAS, 2007; NETO, 2007; RODRIGUES, 2008).

Lima e Rocha (2016) elaboraram formulações de doce de leite com diferentes concentrações de soro, com objetivo de estudar a viabilidade econômica da produção desse produto. Foram realizados cálculos de investimentos físicos e financeiros e obtiveram resultados que indicaram que a formulação com maior porcentagem de soro se mostrou mais lucrativa, se apresentando assim, como um produto com excelente potencial e viabilidade econômica para ser fabricado.

Fernandes et al. (2015) utilizaram o soro de leite para obtenção de filmes biodegradáveis a partir do concentrado proteico de soro irradiado, visando avaliar a sua eficiência como embalagem para maçã. Foram produzidos e avaliados os filmes com o concentrado proteico sem tratamento e outros submetidos por irradiação gama. A partir dos resultados, foi possível concluir que o produto irradiado apresentou aplicabilidade para ser utilizado em embalagens alternativas com intuito em preservar a cor e retardar o escurecimento da maçã após o corte.

\subsubsection{Utilização do leitelho}

A quantidade de leitelho gerado por dia no Brasil ainda não é divulgada precisamente. Essa realidade é provavelmente devido ao déficit no controle do registro de produção, o qual é feito basicamente nas grandes unidades beneficiadoras e por ser comum misturar-se o leitelho com soro advindo da fabricação de queijos. De forma geral, sabe-se que a produção 
deleitelho é em grande volume, pois para cada $\mathrm{Kg}$ de manteiga produzida, tem-se um valor similar ao do leitelho (CAVALARI, 2017).

A maioria dos trabalhos existentes sobre a utilização do leitelho é relacionado a bebidas lácteas. Assim como o soro de leite, existem também bebidas funcionais com características nutritivas produzidos a base de leitelho.

Hiroki et al. (2013) utilizaram o leitelho para elaborar quatro formulações de leite fermentado probiótico com baixo teor de lactose adicionado de culturas probióticas e $30 \%$ de leitelho. O leite fermentado é defino por Carneiro (2012) como o leite inoculado com culturas iniciadoras de microrganismos ácido-láticos, que convertem parte da lactose do leite em ácido lático por meio da fermentação, nome genérico dado aos produtos como: iogurte, leite cultivado, leite acidófilo, kefir, kumys e coalhada. O produto citado fez uso das propriedades funcionais do leitelho para classificá-lo como probiótico e obtiveram ótimos resultados.

Pfrimer (2018) elaborou uma bebida láctea fermentada e saborizada com polpa de cagaita com sete formulações de diferentes concentrações de leite, mistura soro/leitelho e polpa de cagaita. Foram avaliadas as suas características físico-químicas, microbiológicas e aceitação sensorial, as quais apresentaram resultados dentro do padrão estabelecido pela legislação e altas notas na análise sensorial e intenção de compra.

Ribeiro (2012) também utilizou o leitelho para produção de uma bebida láctea fermentada, só que em vez de introduzir uma mistura de soro/leitelho, fez uma substituição parcial e total do soro de leite por leitelho. Após as análises, foi possível concluir que essa substituição não interferiu no processo de fermentação e nas populações dos microrganismos adicionados, além de proporcionar um aumento na viscosidade e na quantidade de minerais do produto final.

Cavalari (2017) desenvolveu uma bebida láctea fermentada com adição de iogurte natural e leitelho. Foram realizadas análises sensoriais de teste de aceitação, intenção de compra e escala do ideal para doçura e textura. Em relação ao teste de aceitação e intenção de compra, obtiveram ótimas notas pelos provadores, já o ideal para doçura e textura, ficaram entre ligeiramente menor que o ideal e ideal. Ainda assim, não descarta a possibilidade do leitelho ser uma ótima opção para o uso em bebidas compostas.

Teixeira (2013) desenvolveu uma bebida simbiótica substituindo o soro lácteo por leitelho em diferentes concentrações com a adição de leite integral, açúcar, inulina, frutooligossacarídeo e culturas láticas probióticas. O produto obteve boa aceitação em relação as propriedades organolépticas e impressão global dos consumidores, favorecendo a fabricação dessa bebida e a chance de sucesso para o mercado de alimentos funcionais. 
Outro tipo de bebida estudada e desenvolvida, foi o kefir, definida por Dias (2016) como um leite fermentado produzido artesanalmente a partir da fermentação do leite pelos grãos de kefir que contêm uma população estável de micro-organismos, resultando em um produto de propriedade ácida e de levemente alcoólico. Monteiro e Gomes (2018) avaliaram o efeito da substituição de leite por leitelho na produção de kefir com dois tratamentos distintos e obtiveram resultados de uma aceitação sensorial similar ao do produto produzido com leite.

Em informações citadas anteriormente, vimos que o leitelho é rico em fosfolipídios, componente que apresenta funções nutricionais e efeitos benéficos para a saúde do consumidor. O leitelho na forma fluida possui uma concentração de fosfolipídios totais de sete a nove vezes maior do que no leite fluido desnatado (CHRISTIE; NOBLE; DAVIES, 1987). Posto isso, o seu aproveitamento como substituto do leite fluido desnatado seria uma opção interessante para formulação de alimentos funcionais. A exemplo disso, Assumpção (2013) desenvolveu uma ricota com adição do leitelho em substituição ao leite desnatado e os resultados mostraramque não houve diferença significativa quanto aos aspectos sensoriais e ao rendimento esperado, apresentando-se como uma das alternativas de utilização para evitar o seu descarte.

O uso de tecnologias favorece um aumento na diversidade de produtos, uma vez que é possível elaborar ingredientes e adicioná-los na formulação de alimentos. A título de exemplo, Costa (2008) desenvolveu um ingrediente lácteo enriquecido em fosfolipídios do leitelho a partir da associação de duas tecnologias de fracionamento: a ultrafiltração e a extração com fluido supercrítico (EFS). A partir dos resultados obtidos do ingrediente lácteo, pôde-se concluir que é possível fabricar leitelho em pó através dessas tecnologias e utilizá-lo como ingrediente especialmente em alimentos de baixo $\mathrm{pH}$.

Juliano et al. (2014) fabricaram uma sobremesa láctea utilizando como base proporções de leitelho: leite com e sem a presença de emulsificante, denominada de "sobremesa láctea tipo frozen yogurt" com características funcionais. Frozen yogurt é uma sobremesa fermentada e congelada similar ao valor nutricional do iogurte com o sabor refrescante do sorvete e que possui baixo teor de gordura e lactose (GOFF, 2011). No trabalho citado, todas as formulações independente da proporção leitelho: leite apresentaram maior rendimento e dureza com a presença de emulsificante, mostrando um retorno positivo no fabrico deste produto.

Outra sobremesa a ser destacada é o sorvete, bastante requerida no cenário mundial por agradar todo e qualquer tipo de público. A aplicabilidade do leitelho em sorvetes se 
apresenta como uma alternativa para aqueles que pretendem consumir sobremesas com menos teor de gordura. Walus (2014) elaborou um sorvete com adição de leitelho e substituição parcial de gordura e os resultados das análises físico-químicas mostraram que esse procedimento não teve influência direta no comportamento e nas características físicas de sorvete. Logo, pôde-se concluir que é possível o uso do leitelho em substituição parcial da gordura do sorvete.

Além disso, pode-se fazer também o uso do leitelho no desenvolvimento de alimentos na panificação, no entanto, essa área de estudo é pouco explorada. Nesse âmbito, Gonzalez et al. (2009) realizaram um estudo sobre o adição do leitelho na formulação de pães. Após a obtenção do produto, foi realizada uma avaliação sensorial por meio do teste de escala hedônica e os resultados das amostras apesentaram que não houve diferença significativa ao nível de 1\% comparados aos pães sem o leitelho, além de obter aceitabilidade dos avaliadores. Em vista disso, a fabricação de pães com adição de leitelho se apresenta viável devido a permanência das características físicas de pão e sabor a gosto dos consumidores.

\section{Considerações Finais}

A partir da revisão bibliográfica, conclui-se que o soro de leite e o leitelho podem dar origem a uma série de produtos, sendo utilizado tanto na forma fluida quanto em pó (por meio da aplicação de tecnologias), enriquecendo o valor nutricional dos alimentos e auxiliando na redução dos impactos ambientais.

Também foi notório que esses subprodutos tem sido tema de muitos trabalhos científicos ao longo dos anos, no entanto, existem mais estudos a respeito da utilização do soro de leite comparado aos estudos realizados sobre o uso do leitelho. Isto deve ser resultado da maiorquantidade de produtos disponíveis a base de soro de leite no mercado. $\mathrm{O}$ soro proveniente da fabricação de queijo corresponde a um volume expressivo na indústria alimentícia brasileira, logo existe soro lácteo em abundância comparado ao leitelho e por isso mais preocupação com o seu descarte inadequado e aproveitamento. Atualmente, a produção e o consumo de manteiga está em crescimento, o que retornaria em mais subproduto e maior possibilidade de ser mais explorado comercial e academicamente.

Além disso, outro ponto verificado com a revisão bibliográfica foi a praticidade dos dois subprodutos abordados. Além de possuírem baixo custo para as indústrias, já que são resultantes de processos de fabricação, eles podem ser utilizados de forma fluida em diversos produtos sem a necessidade do uso de tecnologias, sendo um bom aspecto para as indústrias de pequeno e médio porte. 
Finalmente, ficou evidente a necessidade de uma mudança de tratamento no que se refere ao desuso do soro de leite e do leitelho durante a fabricação de produtos, ou seja, observálos como potenciais fontes de lucro e não como resíduos. Para isso é preciso uma organização industrial que possibilite o encaminhamento dos mesmos para serem processados, dessa forma é possível aproveitar as suas propriedades nutritivas e desenvolver ações tecnológicas vinculadas à industrialização, podendo introduzi-los em diversos alimentos comerciais.

\section{Referências}

ALVES, M. P.; MOREIRA, R. de O.; JÚNIOR, P. H. R.; MARTINS, M. C. F.; PERRONE, Í.

T.; CARVALHO, A. F. Soro de leite: tecnologias para o processamento de coprodutos. Revista do Instituto Laticínios Cândido Tostes, Juiz de Fora, v. 69, n. 3, p. 212-226, maio/jun. 2014.

ANTUNES, A. E. C.; LISERRE, A. M.; FARIA, E. V.; YOSUYANAGI, K.; LERAYER, A. L. S. Buttermilk probiótico. Alim. Nutr., Araraquara, v. 23, n. 4, p. 619-629, out./dez. 2012.

ARAÚJo, N. G; ARAÚJO, P. M. A. G; SAMPAIO, S. B. Elaboração de Pão de Forma Enriquecido com Soro de Queijo. Disponível em: $<$ https://cienciadoleite.com.br/noticia/292 5/elaboracao-de-pao-de-forma-enriquecido-comsoro-de-queijo>. Acesso em: 03 jul. 2020.

ARRAIS, Bárbara C. D. Desenvolvimento de ricota funcional: avaliação das características físico-químicas e microbiológicas do produto. Dissertação de Mestrado. Londrina, $2015 . \quad$ Disponível em: http://repositorio.pgsskroton.com.br/bitstream/123456789/719/1/DESEN VOLVIMENTO\%20DE\%20RICOTA\%20FUNCIONAL.pdf>. Acesso em: 23 jun. 2020.

ASSUMPÇÃO, Giovana M.P.; PAULA, Alcimara A. A. De. Utilização do leitelho na fabricação da ricota em substituição ao leite desnatado. Disponível em: <https://www. fatecourinhos.edu.br/retec/index.php/retec/article/view/38/96>. Acesso em: 27 jun. 2020.

BADISSERA, A. C.; BETTA, F. D.; PENNA, A. L. B.; LINDNER, J. de D. Alimentos funcionais: uma nova fronteira para o desenvolvimento de bebidas protéicas a base de soro de leite. Semina: Ciências Agrárias, Londrina, v. 32, n. 4, p. 1497-1512, out./dez. 2011.

BANASZEWSKA, A.; CRUIJSSEN, F.G.; CLAASSEN, G. D. H.; VAN DER VORST, J.G.A.J. Effect and key factors of byproducts valorization: The case of dairy industry. Journal of dairy science, v. 97, n.4, p. 1893-1908, 2014.

BEDENDO, Anandra et al. Substituição de leite em pó por concentrado proteico de soro de leite (WPC - WheyProteinConcentrate) para elaboração de bolo sem glúten. Braz. J. of Develop, Curitiba, v. 5, n. 7, p. 8062-8073 jul. 2019.

BRANDÃO, W.A.P.L.N.T.M. et al. Bebida fermentada probiótica de soro de leite. Higiene Alimentar, v.20, n.143, p.56-59, 2006.

BRASIL. Ministério da Agricultura. Regulamento Técnico de Identidade e Qualidade para 
Bebidas Lácteas. Instrução normativa $n^{\circ} 16$ de 23 de agosto de 2005. Diário Oficial da União da República Federativa do Brasil, Brasília, seção 1, p. 7, 2005.

BRASIL. Regulamento de Inspeção Industrial e Sanitária de Produtos de Origem Animal (RIISPOA). Decreto $\mathbf{n}^{\mathbf{0}}$ 9.013, 29 de março de 2017. Disponível em: <http://www3. servicos.ms.gov.br/iagro_ged/pdf/2511_GED.pdf>. Acesso em: 23 jun. 2020.

CALDEIRA, Luciana A. et al. Desenvolvimento de bebida láctea sabor morango utilizando diferentes níveis de iogurte e soro lácteo obtidos com leite de búfala. Ciência Rural, $\quad$ v.40, n.10, p.2193-2198, $2010 . \quad$ Disponível em: $<$ http://www.scielo.br/scielo.php?script=sci_ar $\quad$ ttext\&pid=S010384782010001000023\&lng=en\&nrm=iso>. Acesso em: 27 jun. 2020.

CALDAS, M.C.S. Aproveitamento de soro de leite na elaboração de pão de forma. Dissertação de Mestrado. UFPB João Pessoa, 2007.

CARNEIRO, C. da S.; CUNHA; F. L.; CARVALHO, R. de; CARRIJO, K. de F.; BORGES, A.; CORTEZ, M.A.S. Leites fermentados: histórico, composição, características físico químicas, tecnologia de processamento e defeitos. PUBVET, Londrina, V. 6, N. 27, Ed. 214, Art. 1424, 2012.

CARVALHO, G. S. de; SILVA, L. M. da; COELHO, K. O.; BUENO, C. P.; NEVES, R. B. S.

Aproveitamento do soro para a produção de pães de queijo. Disponível em: <https://www.anais.ueg.br/index.php/cepe/article/view/5413/3210>. Acesso em: 24 de jun. 2020.

CAVALARI, Izabel C. da S. Elaboração de bebida fermentada com utilização de leitelho. Trabalho de conclusão de curso (Técnico em alimentos integrado ao ensino médio) - Instituto Federal de São Paulo -Campus Barretos, 2017.

COSTA, Marcela de R. Obtenção de ingrediente lácteo enriquecido em lipídeos polares a partir de leitelho de soro. Dissertação de Doutorado. UNICAMP, Campinas, SP, 2008. Disponível em: http://repositorio.unicamp.br/jspui/handle/REPOSIP/255201. Acesso em: 04 jun. 2020.

CHRISTIE, W. W.; NOBLE, R C.; DAVIES, G. Phospholipids in milk and dairy products. Journal of the Society of Dairy Technology, v. 40, p. 10-12, 1987.

CRUZ, A. G.; SANT'ANA, A. S.; MACCHIONE, M. M.; TEIXEIRA, Â. M. \& SCHMIDT, F.L. Milk drink using whey butter cheese (queijo manteiga) and acerola juice as a potential source of vitamin C. Food Bioprocess Technology, v.2, n.4, p.368-373 2009. Disponível em:

<http://www.springerlink.com/content/4822tp722q3j865j/fulltext.pdf >. Acesso em: 06 jul. 2020.

CRUZ, A.G.; ZACARCHENCO, P.B.; OLIVEIRA, C.A.F.; CORASSIN, C.H. Química, Bioquímica, Analise Sensorial e Nutrição no Processamento de Leite e Derivados. Coleção Lácteos. Rio de Janeiro: Elsevier, 2015.

DELGADO, N. A. A inovação sob a perspectiva do desenvolvimento sustentável: os casos 
de uma cooperativa de laticínios brasileira e de outra francesa. Porto Alegre, 2007. Dissertação (Mestrado em Administração). Programa de pós-graduação em Administração, Universidade Federal do Rio Grande do Sul.

DELGADO, N. A.; BARIN-CRUZ, L. As Inovações no Setor de Laticínios: o Caso do Grupo Cooperativo Francês 3A. In: Encontro da Associação Nacional de Pós Graduação e Pesquisa em Administração, 2007, Rio de Janeiro. XXXI EnANPAD, 2007.

DIAS, P. A. et al. Propriedades antimicrobianas do Kefir. Arq. Inst. Biol., v.83, 1-5, e0762013, 2016.

EMBRAPA. Anuário Leite 2019. Disponível em: < https://ainfo.cnptia.embrapa.br/digital/b itstream/item/198698/1/Anuario-LEITE-2019.pdf>. Acesso em: 23 jun. 2020.

FERNANDES, A. P. S.; COSTA, J. B.; SOARES, D. S. B; MOURA, C. J.; SOUZA, A. R. G. Aplicação de filmes biodegradáveis produzidos a partir de concentrado proteico de soro de leite irradiado. Pesq. Agropec. Trop., Goiânia, v. 45, n. 2, p. 192-199, abr./jun. 2015.

FONG, B.Y.; NORRIS, C.S.; MACGIBBON, A.K.H. Protein and lipid composition of bovine milk-fat-globule membrane. International Dairy Journal, v.17, n.4, p.275-288, 2007. GONZALEZ, S. L. Elaboração de pães com adição de soro de manteiga. Ambiência Revista do Setor de Ciências Agrárias e Ambientais V. 5 N. 3 Set./Dez. 2009.

GOFF, H. D. Ice cream and frozen desserts: product types. In: Encyclopedia of dairy sciences, $2^{\circ}$ ed. Academic Press, London, U K, v.2 p.893-912, 2011.

HARAGUCHI F.K.; ABREU W.C.; PAULA H. Proteínas do soro do leite: composição, propriedades nutricionais, aplicações no esporte e benefícios para a saúde humana. Revista Brasileira de Nutrição, 19(4):479-488, jul./ago., Campinas, 2006.

HIROKI, Ana P. et al. Elaboração de leite fermentado probiótico com baixo teor de lactose e adição de leitelho. Disponível em:

<https://proceedings.science/slaca/slac a2013/trabalhos/elaboracao-de-leite-fermentadoprobiotico-com-baixo-teor-de-lactose-eadi cao-de-leitelho?lang=pt-br>. Acesso em: 23 jun. 2020.

JULIANO, R. S. et al. Desenvolvimento de sobremesa láctea tipo frozen yogurt com características funcionais. Florianópolis, 2014. Disponível em: $<$ http://pdf.blucher.com.br.s31.amazonaws.com/chemicalengineeringproceedings/cobeq2014/0412-25631-159563. pdf >. Acesso em: 24 jun. 2020.

KEMPKA, Aniela P. et al. Formulação de bebida láctea fermentada sabor pêssego utilizando substratos alternativos e cultura probiótica. Ciência e Tecnologia de Alimentos, Supl.28, p.170-177, 2008. Disponível em: <http://www.scielo.br/pdf/cta/v28s0/27.pdf>. Acesso em: 28 jun. 2020.

KREUTZ, D.H.; LEHN, D.N.; SOUZA, C.F. V. de. Efeito da adição de soro de queijo sobre as características sensoriais de bebidas lácteas fermentadas sabor uva. Disponível em: < http://www.univates.br/revistas/index.php/destaques/article/view/246/0> . Acesso em: 04 jul. 2020. 
KUBOTA, Flávio I. Teoria da solução inventiva de problemas integrada à produção mais limpa. Dissertação de Mestrado. Santa Maria, 2012.Disponível em: < https://repositorio.ufsm.br/bitstream/handle/1/8222/KUBOTA\%2C\%20FLAVIO\%20ISSA O. pdf? sequence=1\&isAllowed=y>. Acesso em: 03 de jul. 2020.

LEITE, M.T.; BARROZO, M.A.D.S.; RIBEIRO, E.J. Canonical analysis technique as an approach to determine optimal conditions for lactic acid production by lactobacillus helveticus ATCC 15009. International Journal of Chemical Engineering, v. 2012, p. 1-9. Disponível em: < https://www.hindawi.com/journals/ijce/2012/303874/>. Acesso em: 25 jun. 2020.

LIMA, F. R. S. \& ROCHA, L. de O. Aproveitamento do soro de leite proveniente da produção do queijo do Serro para fabricação de doce de leite: Viabilidade econômica. Rev. Inst. Laticínios Cândido Tostes, Juiz de Fora, v. 71, n. 2, p. 83-93, abr/jun, 2016.

LIMA, S. M. C. G.; MADUREIRA, F. C. P.; PENNA, A. L. B. Bebidas lácteas - nutritivas e refrescantes. Milkbizz Tecnologia Temático, v. 1, n. 3, p. 4-11, 2002.

MACHADO, Rosângela M. G.; SILVA, Patrícia, C. Da; FREIRE, Valdir H. Controle ambiental em indústrias de laticínios. Disponível em: $<\mathrm{http}: / / \mathrm{www}$. signuseditora.com.b r/ba/pdf/07/07\%20-\%20Gestao.pdf >. Acesso em: 26 jun. 2020.

MATOS, R.A. Desenvolvimento e mapa de preferência externo de bebida láctea à base de soro e polpa de graviola (Annona muricata). 2009. 79f. Dissertação (Mestrado em Engenharia de processos de Alimentos) - Curso de Pós-graduação em Engenharia de Alimentos, Universidade Estadual do Sudoeste da Bahia, BA.

MONTEIRO, Paulo S.; GOMES, Paôla da S. Produção de kefir como uma alternativa para a utilização de leitelho. Rev. Inst. Laticínios Cândido Tostes, Juiz de Fora, v. 73, n. 3, p. 162- 171, jul/set, 2018.

MOREIRA, A.; SILVA, A.; ANTUNES, M. (2000) Soro de leite: de resíduo a alimento. Alimentos e Nutrição, v. 4, p. 32-35.

NETO, B.A de M. Aproveitamento de soro de leite de cabra na elaboração de pão de forma. Dissertação de Mestrado. UFPB João Pessoa, 2007. Disponível em: http://livros01.livrosgratis.com.br/cp045882.pdf. Acesso em: 01 jun. 2020.

NOH, S.K. \& KOO, S.L. Milk sphingomyelin is more effective than egg sphingomyelin in inhibiting intestinal absorption of cholesterol and fat in rats. Journal of Nutrition, v.134, p.2611-2616, 2004.

OLIVEIRA, Gleyciane I.C. et al. Alimentação e suplementação de ferro em uma população de lactentes carentes. Revista de Pediatria, v.28, n.1, p.18-25, 2006. Disponível em:

<http://www.pediatriasaopaulo.usp.br/upload/pdf/1153.pdf〉. Acesso em: 26 Jul. 2020.

PESCUMA, Micaela et al. Functional fermented whey-based beverage using lactic acid 
bacteria. International. Journal of Food Microbiology, v.141, p.73-81, 2010.

PFRIMER, Renata $T$. Desenvolvimento e avaliação de bebida láctea fermentada acrescida de leitelho e saborizada com polpa de cagaita. Disponível em: < https://repos itorio.bc.ufg.br/tede/handle/tede/8290>. Acesso em: 26 jun. 2020.

PINTO, Graciele F. de S. Determinação de Triptofano em Queijo Ricota. Trabalho de Conclusão de Curso - Fundação Educacional do Município de Assis - FEMA -- Assis, 2010. Disponível em: < https://cepein.femanet.com.br/BDigital/arqTccs/0711290945.pdf>. Acesso em: 11 jul. 2020.

RIBEIRO, Priscila Costa. Utilização do leitelho para produção de bebida láctea probiótica. 2012. 42 f. Dissertação (Mestrado em Ciência e Tecnologia do Leite) - Centro de Ciências Biológicas e da Saúde, Universidade Norte do Paraná, Londrina, 2012.

RODRIGUES, Andréia P. et al. Elaboração de sorvete sabor chocolate com teor de gordura reduzido utilizando soro de leite em pó. Vetor, Rio Grande, 16(1/2): 55-62, 2006.

RODRIGUES, Fabiola F. G. Elaboração de pão de forma com adição de concentrado protéico de Soro de leite. Dissertação de Mestrado. UFPB João Pessoa, 2008. Disponível em: http://livros01.livrosgratis.com.br/cp066973.pdf. Acesso em: 29 jun. 2020.

ROHFLES, Ana Lúcia B. et. al. Aproveitamento de agroindústrias do setor queijeiro para desenvolvimento de produtos alimentícios e redução de impacto ambiental. TECNOLÓGICA, Santa Cruz do Sul, v.18, n.1, p. 13-18, jan./jun. 2014.

ROSENTHAL, Amauri. Aproveitamento de soro de leite de pequenas queijarias. In: EMBRAPA. Disponível em: < https://www.embrapa.br/busca-de-projetos/-/projeto/20 7283/aproveitamento-de-soro-de-leite-de-

pequenasqueijarias\#: :text=0\%20aproveitamento $\%$

20do\%20soro\%20de,soro\%20ou\%20de\%20seus\%20subprodutos.>. Acesso em: 27 jun. 2020 .

SANTOS, Calila T. et al. Elaboração e caracterização de uma bebida láctea fermentada com polpa de umbu (Spondias tuberosa sp.). Revista Brasileira de Produtos Agroindustriais, v.8, n.2, p.111-116, 2006. Disponível em: <http://www.deag.ufcg.edu.br/rbpa//rev 82/Art823.pdf>. Acesso em: 08 jul. 2020.

SANTOS, Calila T. et al. Influência da concentração de soro na aceitação sensorial de bebida láctea fermentada com polpa de manga. Alimentos e Nutrição, v.19, n.1, p.55-60, 2008. Disponível em: <http://serv-bib.fcfar.unesp.br/seer/index.php/alimentos/article/view File/199/204>. Acesso em: 29 jun. 2020.

SGARBIERI, Valdemiro C., Revisão: Propriedades estruturais e físico-químicas das proteínas do leite. Brazilian Journal of Food Technology, v.8, n.1, p. 43-56, jan./mar., 2005. SILVA, Cláudia V. Da. Desenvolvimento de uma mistura láctea a base de soro de leite em substituição ao leite condensado para emprego na produção de sobremesas industriais. Disponível em: $<\mathrm{https}$ ://repositorio.ufmg.br/bitstream/1843/BUBDAHSN27/1/desenvolvime nto_de_uma_mistura_1_ctea_a_base_de_soro_de_leite_em substitui_o_ao_leite_condensa do_para_emprego_na_produ 1.pdf $>$. Acesso em: 3 jul. 
2020.

SILVA, Carlos A. et al. Utilização de soro de leite na elaboração de pães: estudo da qualidade sensorial. Revista Brasileira de Produtos Agroindustriais, Campina Grande, v.13, n.Especial, p.355-362, 2011.

SILVA, Danilo J. P. da. Resíduos na indústria de laticínios. Disponível em: < https://www2.cead.ufv.br/sgal/files/apoio/saibaMais/saibaMais2.pdf >. Acesso em: 31 jul. 2020.

SIQUEIRA, Amanda de M. O.; MACHADO, Erilane de C. L. and STAMFORD, Tânia L. M. Bebidas lácteas com soro de queijo e frutas. Cienc. Rural [online]. 2013, vol. 43, n9, pp. 1693-1700. ISSN 0103-8478.

SOARES, D. S. et al. Aproveitamento de soro de queijo para a produção de iogurte probiótico. Arq. Bras. Med. Vet. Zootec. vol.63 no.4 Belo Horizonte Agos. 2011.

SOARES, Jéssica P. et al. Efeito da adição de proteína do soro do leite como substituto do trigo na formulação de bolos sem adição de açúcar. Braz. J. Food Technol. vol.21. Campinas 2018 Epub Nov 13, 2017.

SOUZA, Simone L.Q. de. Gestão ambiental na indústria de laticínios: aplicação da produção mais limpa. Disponível em: <https://pdfs.semanticscholar.org/a8cf/91a79d689 959198a8d6a1a4d4779a7dcdf09.pdf>. Acesso em: 26 jun. 2020.

VETTORELlO, G.; DALCORSO. A. B.; BETTI, J.; KEMERICH. G. T.; OLIVEIRA, E. C. Elaboração de sorvete com adição de soro de queijo em pó. Revista Destaques Acadêmicos, Lajeado, v. 9, n. 4, 2017.

VIDAL, A. M.; DIAS, D. O.; MARTINS, E. S. M.; OLIVEIRA, R. S.; NASCIMENTO, R. M.

S.; CORREIA, M. das G. da S. A ingestão de alimentos funcionais e a sua contribuição para a diminuição da incidência de doenças. Cadernos de Graduação - Ciências Biológicas e da Saúde. Aracaju v. 1, n.15, p. 43-52, out. 2012.

VOURCH M.; BALANNEC, B.; CHAUFER, B.; DORANGE, G. Treatment of dairy industry wastewater by reverse osmosis for water reuse. Desalination, v. 219, p. 190-202, 2008.

TEIXEIRA, Stella M. B. Utilização do leitelho no desenvolvimento de bebida simbiótica. Disponível <http://repositorio.ufla.br/jspui/bitstream/1/4562/1/TESE_Utiliza\%c3\%a7\%c3

$\%$ a3o\%20de\%20leitelho\%20no\%20desenvolvimento... pdf $>$. Acesso em: 28 jun. 2020.

TERRA, Nelcindo N.et al. Emprego de soro de leite líquido na elaboração de mortadela. Disponível em: <https://www.scielo.br/scielo.php?pid=S0103-84782009000300038\&scrip t=sci_arttext $>$. Acesso em: 01 jul. 2020.

SMITHERS, GW. Whey and whey proteins: from "gutter to gold". International Dairy Journal. 2008;18:695-704. Disponível em: <https://www.sciencedirect.com/science/article/ab s/pii/S0958694608000344. Acesso em: 
09 jul. 2020.

WALUS, Cláudia. Sorvete com adição de leitelho e substituição parcial de gordura. 2014. Trabalho de Conclusão de (Curso Tecnologia em Alimentos) - Universidade Tecnológica Federal do Paraná. Ponta Grossa, 2014. Disponível em: <http://repositorio.roca.utfp r.edu.br/jspui/bitstream/1/8056/1/PG_COALM_2014_2_22.pdf >. Acesso em: 09 jul. 2020.

ZOELLNER, S.S. et al. Whey beverage with açai pulp as a food carrier of probiotic bacteria. Australian Journal of Dairy Technology, v.64, n.2, p.165-169, 2009. Disponível em: <http://cat.inist.fr/?aModele=afficheN\&cpsidt=22157872>. Acesso em: 03 jul. 2020. 